\title{
ANTHROPOLOGISCHE BESCHOUWING OVER HET SCHULDGEVOEL.*
}

De bestudering van het schuldgevoel brengt ons op de moeilijkste velden van de zielkunde. Wordt hiermede bedoeld een inzicht, een intuitief, dan bevinden we ons op het terrein van de existentiële zekerheden met of zonder haar dialectische tegenspraak. Wordt hiermede aangeduid een "aangedaan zijn", dan is het in dit beleven ons gemoed, onze gestemdheid betrokken.

In het eerste geval zouden we misschien kunnen spreken van schuldbesef of schuldbewustzijn. Hierin zit een sterk rationeel moment, een zich rekenschap geven, waardoor het beleven zich a.h.w. verdicht tot iets concreets, waarbij het concrete (in casu de schuld) in een bijzondere relatie tot mij staat, mij iets te zeggen heeft. In schuldbewustzijn zie ik de schuld als een bespeurbare grootheid, verdicht zich de doorleving tot een tastbaarheid, tot een aanwezigheid, tot een directheid, die grijpbaar wordt.

In schuldbesef hebben we een begrip, dat tussen schuldgevoel en schuldbewustzijn in staat. Beseffen betekent (volgens het etymologisch woordenboek van FRANCK-VAN WIJK) smaken, bemerken, gevoelen, denkvermogen hebben. Het is verwant met het Latijnse „sapio" ( $=i k$ smaak, ruik, ben verstandig). In het Middel-Nederlands komt het in die betekenis voor. Als de hedendaagse gangbare opvatting kunnen we het omschrijven als het „duidelijk gevoel van iets hebben", hetzij al of niet beschouwd als een gevolg van iets te begrijpen. In schuldbesef zit een verstandelijk element, ook al betekent dit nog niet: inzicht in de oorzaak en de mate van de schuld.

De verbinding schuld en gevoel echter plaatst dit begrip in die groep van complexe belevingsgrootheden, die gelijk plichtsgevoel, eergevoel, sympathiegevoel behoren tot de phaenomenen, welke zich niet gemakkeliijk als objecten laten hanteren en waarin feitelijk altijd het gevoelsmoment in de betekenis van gestemdheid domineert. In de benaming schuldgevoel zit iets, dat van grote betekenis is en wat direct voor zichzelf

*Lesing aan studente van ons Universiteit gegee op 21 Aug. 1953. (Die Red.) 
spreekt, indien we nagaan, wanneer we van ,gevoel” spreken. Wat ik voel, dat is van mij, dat is innig met mij verbonden, dat staat niet buiten mij, waar dat is in mij, is van mij zelf. Of ik nu bedoel aanraking, of intuitief inzicht, of de hedonalgische reactie of gemoedsgesteldheid, altijd is het iets, dat zeer bepaald aan mijzelf gebonden is, gelijk het is uitgedıukt in het woord van SCHILLER: „Allen gehort was Du denkst, dein eigen ist nur was Du fühlst." Of wij nu in het begrip schuldgevoel iets meer het accent leggen op de existensiële zekerheid dan wel op de ongrijpbare, niet-discuteerbare gemoedsgesteldheid, in beide gevallen ontmoeten we in het zich-schuldig-voelen een eigen gegevenheid, komen we in het schuldgevoel niet verder dan het getuigenis van de enkeling. $\mathrm{Bij}$ de vraag naar betekenis van onder het schuldgevoel zal elk antwoord dan ook ten nauwste samengeweven zijn met eigen zijnsbeschouwingen en een bij uitstek subjectief karakter hebben.

Want het gevoel geeft wel antwoord op de vraag, wat werkelijk-isvoor-mij, maar het kan zijn, dat ik leef in een waanstemming. De overgang van het schuldgevoel tot het „schuldhebben”, van ,feeling guilty” naar ,being guilty" plaatst ons midden in de anthropologische schuldproblematiek.

Het gevoel zou volgens velen een slechte kenbron zijn voor het verstaan van het wezen der dingen. Wel-is-waar zijn de gevoelsbelevingen betrokken op het beleven der dingen, spreken we van geïntendeerde gevoelsbelevingen, maar daarnaast kennen we de objectloze gevoelens, gelijk angste en geluk, een gestemd zijn, waarin zich zonder meer de wijze van in-de-wereld-zijn openbaart. Toch kunnen we in bijna elk gevoel iets vinden van een betrokken zijn op; er is altijd wel iets, waaraan of waarover wij ons ergeren of verheugen. Men kan hiertegen opmerken, dat in sommige gevoelens, zoals in hongergevoel en moeheidsgevoel, deze gevoelens niet betrokken zijn op het object, maar op het subject, d.w.z. ze worden in de beleving als onmiddellijke bepaaldheden van het zelf ervaren. Het is de onmiddellijk beleefbare inhoud van het zelfbewustzijn. Dit nu geldt ook voor het schuldgevoel. Daarin openbaart zich iets van het zijn in de wereld, van de verhouding tot mij zelf en van de ander tot mij.

Ditzelfde geldt van de begrippen, die met schuldgevoel nauw verbonden zijn, gelijk schaamte, leed, berouw, wroeging. Deze begrippen worden dikwijls behandeld, alsof ze een toestand zonder meer uitbeelden. Toch zijn wij dan in een te statische interpretatie dezer grootheden. Woorden 
als schuld, gêne, schaamte, etc. drukken geen gehypostaseerde eigenschappen uit, doch geven verhoudingen aan. Wij moeten het accent dan ook meer leggen op het dynamisch karakter dezer significa. Woorden als verantwoordelijk, aansprakelijk, schuldig, drukken op zichzelf geen inhoud uit, ze geven allereerst relaties weer.

Zo ook drukken begrippen als berouw, schaamte, meer uit dan een toestand; ze hebben altijd betrekking op een beleving, waarin een ,ingemeenschap-zijn" meebeleefd is.

Hoe staat dit nu met het begrip schuldgevoel? Dit woord komt in het meest klassieke boek, waarin vanaf de eerste pagina gesproken wordt over schaamte en vrees, niet voor. Natuurlijk kent de Bijbel dit complexe phaenomeen met zijn onlustkarakter heel goed. Maar het spreekt van een "verslagen geest", een „gebroken hart", benauwdheid, droefheid-naarGod. De Bijbel spreekt van een bewogenheid van het gemoed, welke door David, Daniet, e.a. met echt-semietische hartstochtelijkheid wordt uitgedrukt. Toch gaat het schuldgevoel hierin niet op. Het is, gelijk PASCAL het uitdrukt: „Ons gemoed geeft zich nooit allesomvattend aan iets". Ons gemoed blijft bij het wezenlijke ten achter en de vraag rijpt, of we in de tonen van ons gemoedsleven, zoals in angste en vrees, spijt en wroeging, wel het meest wezenlijke grijpen van deze beleving. Het Nieuwe Testament kent een ander begrip, nl. metanoia, waarin reeds iets zit van besef, omkeer. We komen daar straks op terug. Ook in ons berouw zit iets van de metanoia, in tegenstelling tot wroeging. Wroeging betekent in de Middeleeuwen: aanklacht, sterk besef van verkeerdheid van een daad. Het mist de bijgedachte aan een voornemen tot verbetering of niet-herhalen; het kan leiden tot wanhoop, is in zich zelf gekeerd.

Berouw is droefheid over iets, dat men heeft gedaan (of nagelaten) en wordt sedert de Middeleeuwen gebruikt met de bijgedachte aan het verlangen naar beterschap. Het wordt ook gebruikt voor „sterk-besef-vanschuld" of van verkeerdheid ener daad en gaat gepaard met een ernstig voornemen te waken voor herhaling, en met behoefte naar verzoening, d.w.z. een verlangen naar herstel van de verbroken relatie. De verloren zoon toonde berouw en staat op en gaat naar zijn vader. Judas krijgt spijt, als hij ziet, dat Jezus veroordeeld is. Natuurlijk heeft hij geweten, dat dat gebeuren zou. Dat was geen toeval, geen samenloop; hij heeft zelf de situatie geschapen, waarin dat zou plaats hebben. Het niet meer te veranderen feit doet hem (na afloop, of misschien reeds tijdens het gebeu- 
ren) schrikken, brengt hem tot bezinning, of misschien direct tot wanhoop, met de daarop volgende zelfmoord. Hij wil goed maken, wat maar enigszins kan. Hij brengt het geld terug en hij spreekt het uit, dat het mis is. $\mathrm{Nu}$ vallen hier twee dingen op. Indien de overpriesters die biecht geaccepteerd hadden, dan is het mogelijk, dat Judas zich maar niet ineens zou hebben gesuïcideerd.

Maar als zij zeggen, wat gaat ons dat aan, dat is jouw zaak, smijt hij het geld weg en vlucht in de dood. Was hem meegevoel getoond, wellicht ware het schuldgevoel berouw geworden. Door de onverschillige houding van de ander wordt schuldgevoel tot wroeging, tot knagend zelfverwijt. Wroeging is berouw, waarbij katharsis is uitgesloten. Was in de tweede ontmoeting met de Farizeërs naar hem geluisterd, dan had deze therapie hem wellicht iets gedaan.

Op deze wijze geformuleerd blijkt het mogelijk, dat in de zich schuldig voelende tegelijk aanwezig is een weet hebben van de objectieve grond van het beleven. Schuldgevoel is dan lijden aan het eigen schuldbesef, lijden om het bestaan van schuld.

Toch is dit lang niet altijd zo duidelijk onderscheiden in de beleving van schuldgevoel. In het zich schuldig voelen hebben we te doen met een bepaald soort gevoelen, waarin het hebben van inzicht, het kennend verstaan, de ,gnosis" in het beleven wordt verkregen. In de beleving wordt althans iets verstaan van wat tot het mens-zijn behoort en in het met-de-ander zijn mogelijk is. Als zodanig behoort het schuldgevoel tot de existentiële of geestelijke gevoelstoestanden, welke heel ons leven doordringen. Schuldgevoel heeft daarin verwantschap met gelukzaligheid, vertwijfeling, extase en begenadiging. Deze gevoelens komen over ons en nemen bezit van ons. Ze doordringen alle levensinhouden, zonder dat we weten hoe en waarom. We noemen ze geestelijke of existentiële gevoelens en willen daarmede het specifiek menselijke karakter van die gevoelens aanduiden. Ze zijn inhaerent aan ons bestaan, aan ons in de wereld en onder de mensen zijn; ze treden op bij het keuze doen, in het bestaan, in de bestaanswijze; ze treden op bij het keuze doen, in het bestaan, in de bestaanswijze als vorm van potentiële existentie. In het bestaan realiseer ik mij zelf, ben ik, die ik kan zijn, beleef ik mij zelf zonder nochtans mij zelf in het bestaan en in het beleven uit te putten. Existeren wil zeggen: er zijn, d.i. het ondoorzichtige, dat wij ergens zijn, ergens bij en ergens buiten, 
het veronderstelt een betrokken-zijn-op. Daarin ligt iets van het geplaatst zijn, van het „ergens-zijn" en "nu beginnen”.

Leven is als zodanig een gebeuren, een continu doorgaan, zonder begin of einde. Beleven, bestaan, existeren omsluit het feit, dat wij ergens geplaatst zijn en daar in de reflexie ons oriënteren, althans trachten te oriënteren, bezig zijn met en zorg hebben voor. Het is een zich oriënteren omtrent het gewordene, omtrent de noodzakelijkheid en de vrijheid; het omsluit het feit, dat de mens zich in het bestaan ervaart en zich nu iets voor kar nemen, het is de beleving van gegeven noodzakelijkheid en daar boven uitgaande mogelijkheid.

Hierin ligt tevens de ontsluiting van de angst-van angst voor de onbestemde mogelijkheden. Sommigen spreken van schuldangst. Afgezien van de betekenis, die daaraan in de psychoanalytische literatuur wordt gegeven, kan dit betekenen, dat het schuldgevoel, inhaerent aan het existeren, innig vervlochten is met angstig zijn. Daarbij treedt de angst veel duidelijker aan de dag dan de schuldbeleving. Angst, zorg, onzekerheid en gebrokenheid ontmoeten we in het uitzichtloze bestaan veel duidelijker dan de schuld. Schuld als zodanig gaat veelal in een bewolking schuil. En toch hebben in Holland velen iets daarvan-in welke vorm ook-doorleefd in de bewogenheid van het verleden. Zoals in het begin van de bezetting, als een medemens, onze naaste zonder vorm van proces uit zijn huis werd gehaald. Later waren we afgestompt. Bij de eerste beleving was er een direct willen ingrijpen. Onze medemens werd zonder geestelijk contact aangegrepen als een physiek gebeuren, als een ding opgenomen en verplaatst. Wij wilden protesteren, maar werden teruggehouden. Een ander die het gedaan had, was eveneens als voorwerp opgenomen en in een voertuig geworpen. Al het menselijke was verdwenen. Onze naaste $w$ as als mens gedevalueerd en wij hadden $\mathrm{cr}$ bij gestaan zonder protest. Ik zelf had bestaan, zoals ik niet wilde bestaan; ik had de gemeenschap geschonden: het was een er-bij-staan en een buiten-mij-zelf-staan, een existeren in schuld: deze man was uit mijn gemeenschap weggehaald, en ik leefde gewoon voort. Aan de avond van zulk een dag komt die onuituisbare beleving: de zon gaat onaier gelijk altijd, de verduistering gaat dicht gelijk te voren. En een machteloze spanning ervaar ik, gelijk het in de MattheusPassion is uitgedrukt na de gevangenneming van Jezus: „Sind Blitze, sind Donner in Wolken verschwunden". In zulk een avond is er een diep doorleefd schuldgevoel. „Ich bin's, ich sollte büssen", maar tegelijk iets van 
angst, van machteloosheid, van zorgvol vragen en ontzetting, dat dit mogelijk was.

Er is schijnbaar een solidariteit tussen mensen en mensen, die mede verantwoordelijk maakt voor alle onrechtmatigheid, met name voor wat er in mijn eigen omgeving, of met mijn medeweten of met mijn toelating gebeurt. Ik voel mij schuldig op een wijze, die juridisch of ethisch niet begrijpelijk is. In deze situatie, dat ik bij de mijnen thuis zit en de ander, van alle „mens-zijn" beroofd, wordt weggevoerd, beleef ik schuld en onrecht. Natuurlijk bedoel ik niet de juridische onrechtmatigheid.

Maar heel mijn gedrag staat onder de code van het in-gemeenschapzijn, onder wat mij moraal noemen, onder de regel, die $i k$ als voor mij gesteld, beleef, de wijze, waarop ik mijzelf ervaar. Het gaat erom, „hoe ik met mij zelf omga en met de ander". Moraal is de code voor de stylering van het leven ten opzichte van mij en cie verhouding tot de ander. In mijn bestaan word ik mij de schuld, inhaerent aan deze bestaansvorm, bewust. Dit zich schuldig voelen is een tot zich zelf komen. In het schuldgevoel wordt mij iets gezegd omtrent mij zelf en mijn staan in de gemeenschap.

Wanneer in het schuldbewustzijn een objectiverend moment ligt en het gevoel als zodanig een op het subject betrokken grootheid is, dan staat het schuldgevoel daar tussen in. Het schuldgevoel is, evenals het pijngevoel, op de persoon zelf betrokken, maar toch ook weer niet als een overigens ongerichte toestand; integendeel, juist in het schuldgevoel wordt de verhouding tot zich zelf en tot de ander beleefd. In het schuldgevoel valt het in-gemeenschap-zija a.h.u. uiteen, ervaart de mens zich als existerend wezen, buiten zich zelf en in een verbroken gemeenschap. En telkens gevoelt hij zijn onbekwaamheid om die gemeenschap te herstellen. Hij moet het en kan niet. Hij wil en wil niet.

Telkens weer moeten wij beslissen, zij het niet zo extreem als toen onze naaste als een ding werd weggesleurd, om of schijnbaar zinloos ons leven te geven en te delen in het lot van de ander, òf er mee te blijven omkomen en dat ik zelf nog besta. Dit „omkomen" wordt hier gebezigd als het omvattend begrip van „door-het-gebeuren-laten-grijpen”.

Het in-gemeenschap-zijn vordert, dat wij gemeenschappelijk bestaan of niet bestaan. Het is een vergrijp aan dit-in-gemeenschap-zijn, dat ik de gemeenschap prijsgeef en nog besta. Hier is een schuldgevoel, een gène, 
cen kosmische schaamte over het er zijn, over:: „dat ik ben, die ik ben" en dat ik niet de ander ben. JASPERS spreekt hier van metaphysische schuld. $\mathrm{Er}$ is geen zedelijke eis mijn leven prijs te geven. Toen GUDDEN, de lijfarts van LUDWIG II van Beieren, zijn vorst, die zich in een vlaag van waanzin in het meer stortte, nasprong en met hem verdronk, kon niemand dat als de aangewezen weg vorderen. Had GUDDEN dit niet gedaan, hij zou de schuld, inhaerent aan zijn bestaan, blijvend hebben gevoeld.

Mijn keuze kan echter nooit zijn een zekere ondergang, wel om mij in cle wereld te bewaren tot een eventuele realisering. Daarin niet slagen, geeft ethisch schuldgevoel. Maar er is een ander schuldgevoel in het ontbreken van een absolute solidariteit met de mens als mens.

Deze solidariteit wordt gelaedeerd, wanneer ik er bij ben, waar onrecht greschiedt, waar een overtreding wordt begaan. Wanneer het gebeurt en ik ben er bij en ik overleef het, dan is er een stem in mij, niet altijd cven duidelijk, maar wel altijd van deze inhoud: „dat het mij niet overkwam en ik heb hem of haar wel liet overkomen, daar sta ik in de schuld".

De mens staat telkens weer in zulke situaties, die met het eindig bestaan onvermijdelijk gegeven zijn en tegelijk het bestaan als zodanig bedreigen. Hier liggen de onverenigbare gegevenheden, welke wezenlijk zijn voor het bestaan. In dit bestaan lijdt de mens aan de spanning, die in het bestaan zelf ligt, lijdt hij aan de kosmische schuld. Telkens weer staat de mens voor een keuze, waarin het de tragiek van zijn bestaan is, dat hij of zij (ondanks een ontwijfelbaar juist inzicht inzake de keuze, die hij doet) schijnbaar noodgedwongen de weg gaat, die hem of haar schuldig stelt. JASPERS spreekt dan van grenssituaties. Hij bedoelt daarmee, dat er niets vooruit vasstaat. Dat elke zekerheid doortrokken is van een dialectische twijfel. Dat zich in elk ,ja", in elke overgave, in elke realisering tegelijk een devalorisatie voltrekt. Deze situaties zijn ondragelijk, komen zelden in volle helderheid tot bewustzijn. Vele mensen hebben reeds vooraf een houvast, leven overeenkomstig autoritaire normen, of halen zich er uit in een stoicijnse vlucht voor dit gevoel.

De meeste mensen beleven deze schuldsituatie niet. Wanneer echter dit gevoel in de vorm van wroeging, zelfverwijt, in de vorm van wanhopig vragen: „waarom moest dit gebeuren, waarom”, optreedt dan kan de mensch in de spanning daarvan bezwijken of transcenderen, gelijk L.UTHER en FRANCISCUS VAN ASSISI die er boven uit kwamen. 
Bij dieper inzicht wordt de structuur, die tot deze grenssituaties voert, steeds duidelijker: In alles, wat wij willen, is in de feitelijke realisering het niet-gewilde begrepen. Met al ons willen is onmiddellijk verbonden een niet willen. In deze antinomie openbaart zich de gebrokenheid, de schuld in het bestaan. De mensch kan niet waarlijk leven zonder schuld. $\mathrm{Er}$ is een spanning tussen niet-gerealiseerde en geïntendeerde waarden. $\mathrm{Er}$ is een gevoel van schaamte vanwege het falen in het actualiseren van onze mogelijke existentie. Geen enkele daad, geen enkel gedrag heeft zuiver het gewild beloop.

Dit schuldgevoel voer dikwijls tot een besliste wending. We kunnen ons in velerlei opzicht eerst dàn een stuk leven ontzeggen, als we vooraf aan het door ons niet gewilde hebben toegegeven. AUGUSTINUS, TOLSTOI, e.a. hebben hun levensvorm gevonden na een bestaan in de wereld. Slechts wie zondaar is, kan ook moreel zijn. Bij elke realisering van waarden staat de mens in de antinomie. Antinomieën maken de schuldbeleving onvermijdelijk.

Het schuldgevoel heeft als zodanig wel-is-waar een negatief accent, maar met een positief prospectief aspect, vooral in het berouw. Dit is schijnbaar in tegenspraak met de gangbare opvatting in onze psychotherapie. Daar willen we het schuldgevoel wegwerken, althans het neurotisch schuldgevoel. Dit kan een vereiste zijn, omdat de mens, die wij in de therapie ontmoeten, zich tot ons wendt met zijn persoonlijke nood. Hij dreigt te bezwijken en dan kunnen we in de overdracht, of in het luisteren, of in het meeleven iets bereiken. Als de patiënt ons deelgenoot mag maken, als hij ons mag betrekken in zijn leed en schuld, dan kunnen wij, gelijk de Farizeërs dat met Judas hadden kunnen doen, helpen. De vraag is echter, of dit bij alle schuldgevoel mogelijk is. We maken n.l. onderscheid tussen het normale schuldgevoel en het abnormale of neurotische schuldgevoel. Het "normale", gewone schuldgevoel treedt op in een homologe gemeenschap, met adaequate verhoudingen, waarin een gelijk gestemdzijn en een harmonische coördinatie heerst, zoals dat b.v. het geval is in het huwelijk, in de vriendschap, in de verhouding tussen ouders en kinderen; het kan ook in een werkgemeenschap worden aangetroffen. Natuurlik vinden we daarin toch altijd wel iets van het „fascinosum", van de verbijstering, het aangedaan worden door het bestaan van de ander. Maar het kenmerk is de liefde en voor zover er sprake is van ",fascinosum" bestaat het wederkerig. In zulk een gemeenschap is alleen plaats voor het indeterminisme. Wordt dit ontkend, dan krijgt schuld een neurotisch 
karakter. Het wilsbesluit resulteert dan uit de sterkte der tegenstrijdige wensen, welke uitsluitend bepaald zijn door doelvoorstellingen (motieven) in verband met de sterkte der neigingen. $E_{r}$ is dan ten eerste geen sprake van echte schuld, aangezien het verwijt gericht is tot de ongeoorloofde neigingen en het verwerpelijk karakter. Men keurt niet de dader af, maar zijn gedrag. Stellen wij er ons op het standpunt dat de dader afkeuring, verwijt treft, dan moeten we het determinisme verwerpen. Van „culpa" is alleen sprake, indien de dader het gevolg van zijn bestaansvorm kan voorzien en wilsmatig de consequenties had kunnen voorkomen gelijk de jeugdige of de vrouw, die met een landloper de bergen ingaat. In dit normale schuldgevoel is sprake van een wil, die in staat is de doelvoorstellingen, de motieven te beïnvloeden.

In dit normale schuldgevoel zit nog een beperking. $\operatorname{Er}$ is alleen schuldgvoel, indien het gedrag negatief gewaardeerd wordt. Opzet zonder meer is kleurloos, behoeft geen schuldgevoel te wekken. Culpa, nalatigheid, on(bed)achtzaamheid, verwaarlozing hebben een negatieve betekenis. Ik kan niet zeggen: ,het is mijn schuld, dat die vrouw gered is". Het gewone (ware) schuldgevoel wijst er altijd op, dat ik mij van mijn gedrag een verwijt kan maken. .

De tweede vorm is het neurotische, alledaagse schuldgevoel. Ook hier wordt de schuld beleefd als een laederen van de gemeenschap, maar dan als van een deficiënte modus van de gemeenschap. De vader is de straffende, de gestrenge-in mij werken de ressentimenten. Daar is geen sprake van een homoloog milieu; hier overheerst het tremendum! Er is geen geliik gestemd zijn, maar een druk van boven naar beneden. Angst is hier: vrees-voor-straf. Hier hebben we een inadaequaat milieu met plaats voor opstand, intrige, realisering van het verbodene, insubordinatie, gevolgd door schuldgevoel. Het kenmerk is het gebod.

Hicr is wel plaats voor het determinisme, gelijk practisch de gehele psychoanalytische literatuur het leven opbouwt uit de wisselwerking tussen de primaire behoeften en de invloeden van de omgeving. Het resultaat wordt bepaald door de krachtverdeling van het veld der werkoorzaken.

Het is van belang te letten op de reactie. De reactie op het echte schuldgevoel of liever de attitude, inhaerent aan het gewone schuldgevoel, is berouw, gepaard met een behoefte aan liefde-versterking, gelijk dat in tegenstelling met Judas het geval was met Petrus. Er is verandering van 
het zelfbewustzijn, metanoia, een breken van de trots; een de mindere willen zijn.

Reactie op het neurotische schuldgevoel is velerlei: inadaequate boetedoening, verweer en vlucht, of de selfmoord. In het neurotisch schuldgevoel hanteer ik een omgrensde aangelegenheid, een grijpbare grootheid, de transcriptie van de levensernst der innerlijke ervaring in een biologische dynamiek van driften.

In het alledaagse, neurotische schuldgevoel is het de hedonalgische reactie, een bepaalde belevingskwaliteit, die zich laat objectiveren beschrijven en ordenen.

Het kosmisch schuldgevoel laat zich niet objectiveren.

Het kosmische schuldgevoel is de zijnsopenbaring van het menszijn. waarin zijn wezen, gelijk hij zichzelf doorlicht—en de wijze, waarop hij in de gemeenschap staat, wordt onthuld. Dit behoeft niet te leiden naar een schuld-emotionalisme, waarbij aan de werkingen van het schuldgevoel een functie wordt toegekend ten aanzien van de ontdekking der ontologisch geïnterpreteerde waarheid.

Wel zien sommigen in de chthonische beroering van oerhuiver en schuldangst een eruptieve manifestatie van de mens, die heengaat uit de gemeenschap ell in de eenzaamheid komt tot het verpletterend gevoel van eigen waardeloosheid en gemeenheid.

Maar naast deze daemonische openbaring kan er een gevoel zijn van schuld in andere zin, een innerlijke omkeer, een berouw, dat zich niet laat verwoorden anders dan in de taal van KIERKEGAARD: het eeuwig blijvend schuldgevoel, dat zich niet in beelden laat uitdrukken; het is incommensurabel, daar elk beeld in het uitbeelden de schuld termineert. Vandaar het onvermijdelijk zwijgen over de laatste innerlijkheid. Die zwijgt beledigt niemand, klaagt niemand aan dan zich zelf.

L. VAN DER HORST. 
karakter. Het wilsbesluit resulteert dan uit de sterkte der tegenstrijdige wensen, welke uitsluitend bepaald zijn door doelvoorstellingen (motieven) in verband met de sterkte der neigingen. $\mathrm{Er}_{r}$ is dan ten eerste geen sprake van echte schuld, aangezien het verwijt gericht is tot de ongeoorloofde neigingen en het verwerpelijk karakter. Men keurt niet de dader af, maar zijn gedrag. Stellen wij er ons op het standpunt dat de dader afkeuring, verwijt treft, dan moeten we het determinisme verwerpen. Van „culpa" is alleen sprake, indien dc dader het gevolg van zijn bestaansvorm kan voorzien en wilsmatig de consequenties had kunnen voorkomen gelijk de jeugdige of de vrouw, die met een landloper de bergen ingaat. In dit normale schuldgevoel is sprake van een wil, die in staat is de doelvoorstellingen, de motieven te beïnvloeden.

In dit normale schuldgevoel zit nog een beperking. $\mathrm{Er}$ is alleen schuldgvoel, indien het gedrag negatief gewaardeerd wordt. Opzet zonder meer is kleurloos, behoeft geen schuldgevoel te wekken. Culpa, nalatigheid, on(bed) achtzaamheid, verwaarlozing hebben een negatieve betekenis. Ik kan niet zeggen: ,het is mijn schuld, dat die vrouw gered is". Het gewone (ware) schuldgevoel wijst er altijd op, dat ik mij van mijn gedrag een verwijt kan maken. .

De tweede vorm is het neurotische, alledaagse schuldgevoel. Ook hier wordt de schuld beleefd als een laederen van de gemeenschap, maar dan als van een deficiënte modus van de gemeenschap. De vader is de straffende, de gestrenge---in mij werken de ressentimenten. Daar is geen sprake van een homolong milieu; hier overheerst het tremendum! $\mathrm{Er}$ is geen gelijk gestemd zijn, maar een druk van boven naar beneden. Angst is hier: vrees-voor-straf. Hier hebben we een inadaequaat milieu met plaats voor opstand, intrige, realisering van het verbodene, insubordinatie, gevolgd door schuldgevoel. Het kenmerk is het gebod.

Hicr is wel plaats voor het determinisme, gelijk practisch de gehele psychoanalytische literatuur het leven opbouwt uit de wisselwerking tusscn dc primaire behoeften en de invloeden van de omgeving. Het resultaat wordt bepaald door de krachtverdeling van het veld der werkoorzaken.

Het is van belang te letten op de reactie. De reactie op het echte schuldgevoel of liever de attitude, inhaerent aan het gewone schuldgevoel, is bcrouw, gepaard met een behoefte aan liefde-versterking, gelijk dat in tegenstelling met Judas het geval was met Petrus. Er is verandering van 
190

het zelfbewustzijn, metanoia, een breken van de trots; een de mindere willen zijn.

Reactie op het neurotische schuldgevoel is velerlei: inadaequate boetedoening, verweer en vlucht, of de selfmoord. In het neurotisch schuldgevoel hanteer ik een omgrensde aangelegenheid, een grijpbare grootheid, de transcriptie van de levensernst der innerlijke ervaring in een biologische dynamiek van driften.

In het alledaagse, neurotische schuldgevoel is het de hedonalgische reactie, een bepaalde belevingskwaliteit, die zich laat objectiveren beschrijuen en ordenen.

Het kosmisch schuldgevoel laat zich niet objectiveren.

Het kosmische schuldgevoel is de zijnsopenbaring van het menszijn, waarin zijn wezen, gelijk hij zichzelf doorlicht-en de wijze, waarop hij in de gemeenschap staat, wordt onthuld. Dit behoeft niet te leiden naar een schuld-emotionalisme, waarbij aan de werkingen van het schuldgevoel een functie wordt toegekend ten aanzien van de ontdekking der ontologisch geinterpreteerde waarheid.

Wel zien sommigen in de chthonische beroering van oerhuiver en schuldangst een eruptieve manifestatie van de mens, die heengaat uit de gemeenschap en in de eenzaamheid komt tot het verpletterend gevoel van eigen waardeloosheid en gemeenheid.

Maar naast deze daemonische openbaring kan er een gevoel zijn van schuld in andere zin, een innerlijke omkeer, een berouw, dat zich niet laat verwoorden anders dan in de taal van KIERKEGAARD: het eeuwig blijvend schuldgevoel, dat zich niet in beelden laat uitdrukken; het is incommensurabel, daar elk beeld in het uitbeelden de schuld termineert. Vandaar het onvermijdelijk zwijgen over de laatste innerlijkheid. Die zwijgt beledigt niemand, klaagt niemand aan dan zich zelf.

L. VAN DER HORST. 